\title{
Ischemia/reperfusion-induced lung injury prevention: many options, no choices
}

\author{
Pedro Caruso ${ }^{1,2}$, Susimeire Gomes ${ }^{1}$
}

The pulmonary parenchyma is prone to injuries caused by indirect insults, such as sepsis, pancreatitis, burn, blood transfusion, bypass surgery, intoxication, and ischemia followed by reperfusion (ischemia/reperfusion injury). Approximately $20 \%$ of all cases of acute respiratory distress syndrome (an extreme case of lung injury) are the result of an indirect insult to the lung parenchyma. ${ }^{(1)}$ However, the exact incidence of lung injury caused by an ischemia/reperfusion insult remains unknown. In the clinical arena, there are frequent situations of ischemia/ reperfusion insults to tissues other than the lungs. Vascular surgery, orthopedic surgery, mesenteric ischemia, trauma, renal ischemia, liver ischemia, and liver transplantation are well-known examples of ischemia/reperfusion insult, and it is not an overstatement to say that such insults are common in the clinical arena.

In the treatment of severe acute lung injury, the guiding principles are treatment of the main cause and the prevention of further lung injury, mainly through protective mechanical ventilation. However, because there is an interval between the ischemia/reperfusion insult and the occurrence of the lung injury, there is an opportunity to and interest in finding drugs to prevent or attenuate the lung injury. Many drugs and procedures have been tested in order to prevent the deleterious effect of the ischemia/reperfusion insult, including hyperbaric oxygen, iloprost, cyclosporine, levosimendan, ascorbic acid, preconditioning with hyperoxygenated solution, tempol (a membrane-permeable radical scavenger), melatonin, rapamycin, pyrrolidine dithiocarbamate, surfactant, inhaled nitric oxide, prion protein, creatine supplementation, catalase, ischemic conditioning maneuvers, and carbon monoxide. Most studies evaluating such drugs and procedures have tested them in small animals, using various models of ischemia/reperfusion, injury quantification scales, and time intervals from the ischemia/reperfusion insult to the injury analysis.

We read with interest the article by Takhtfooladi et al., entitled "Effects of $\mathrm{N}$-acetylcysteine and pentoxifylline on remote lung injury in a rat model of hind-limb ischemia/reperfusion injury", which appears in this issue of the Jornal Brasileiro de Pneumologia. (2) The authors evaluated the protective effect of $\mathrm{N}$-acetylcysteine and pentoxifylline on remote lung injury in a rat model of hind-limb ischemia/reperfusion insult and concluded that $\mathrm{N}$-acetylcysteine and pentoxifylline protect against the consequent oxidative stress and histological damage to the lungs. We found it interesting that administration of the combination of $\mathrm{N}$-acetylcysteine and pentoxifylline does not increase the protective effect. In other experimental studies, many drugs have been shown to minimize the lung injury caused by ischemia/reperfusion. Therefore, we would expect to see many clinical trials testing such drugs. However, the number of published clinical studies addressing the prevention of ischemia/reperfusion injury is disproportionally lower than is that of the experimental studies, and the clinical studies have produced controversial results. The effectiveness of cyclosporine in attenuating ischemia/reperfusion injury caused by percutaneous coronary intervention has been tested, as has that of remote ischemic conditioning in attenuating ischemia/ reperfusion injury after living donor renal transplantation, and neither treatment was found to be effective. ${ }^{(3)}$ The results obtained in clinical studies of $\mathrm{N}$-acetylcysteine as an antioxidant have also been controversial. In one clinical study, N-acetylcysteine effectively attenuated tourniquet-induced ischemia/reperfusion injury following knee surgery ${ }^{(4)}$ whereas other studies have shown that $\mathrm{N}$-acetylcysteine does not attenuate myocardial reperfusion injury in unselected patients with ST-segment elevation myocardial infarction undergoing primary percutaneous coronary intervention ${ }^{(5)}$ or hepatorenal injury in patients undergoing orthotopic liver transplantation. ${ }^{(6)}$ In the clinical arena, pentoxifylline has been less extensively tested than has $\mathrm{N}$-acetylcysteine, and the few studies evaluating the former, such as a study of pentoxifylline for the prevention of delayed graft function in recipients of deceased donor kidney grafts, ${ }^{(7)}$ have reported disappointing results in terms of injury attenuation.

The study conducted by Takhtfooladi et al.(2) shows us that $\mathrm{N}$-acetylcysteine and pentoxifylline both protect the lung parenchyma from the effects of an ischemia/ reperfusion insult. Although this is an interesting finding, further studies are needed in order to test the hypothesis that $\mathrm{N}$-acetylcysteine and pentoxifylline are able, in the clinical arena, to protect the lungs from ischemia/ reperfusion injury or to attenuate such injury.

\section{REFERENCES}

Brun-Buisson C, Minelli C, Bertolini G, Brazzi L, Pimentel J, Lewandowski $\mathrm{K}$, et al. Epidemiology and outcome of acute lung injury in European intensive care units. Results from the ALIVE study. Intensive Care Med. 2004;30(1):51-61. http://dx.doi.org/10.1007/s00134-003-2022-6

2. Takhtfooladi HA, Hesaraki S, Razmara F, Takhtfooladi MA, Hajizadeh H. Effects of $\mathrm{N}$-acetylcysteine and pentoxifylline on remote lung injury in a rat model of hind-limb ischemia/reperfusion injury. J Bras Pneumol. 2016;42(1):9-14

3. Piot $C$, Croisille $P$, Staat $P$, Thibault $H$, Rioufol G, Mewton $N$, et al. Effect of cyclosporine on reperfusion injury in acute myocardial infarction. N Engl J Med. 2008;359(5):473-81. http://dx.doi.org/10.1056/ NEJMoa071142

4. Koca K, Yurttas Y, Cayci T, Bilgic S, Kaldirim U, Durusu M, et al. The role of preconditioning and $\mathrm{N}$-acetylcysteine on oxidative stress resulting from tourniquet-induced ischemia-reperfusion in arthroscopic knee surgery. J Trauma. 2011;70(3):717-23. http://dx.doi.org/10.1097/ TA.0b013e3181f30fb0 
5. Thiele H, Hildebrand L, Schirdewahn C, Eitel I, Adams V, Fuernau G, et al. Impact of high-dose $\mathrm{N}$-acetylcysteine versus placebo on contrastinduced nephropathy and myocardial reperfusion injury in unselected patients with ST-segment elevation myocardial infarction undergoing primary percutaneous coronary intervention. The LIPSIA-N-ACC (Prospective, Single-Blind, Placebo-Controlled, Randomized Leipzig Immediate PercutaneouS Coronary Intervention Acute Myocardia Infarction N-ACC) Trial. J Am Coll Cardiol. 2010;55(20):2201-9. http:// dx.doi.org/10.1016/i.jacc.2009.08.091
6. Hilmi IA, Peng Z, Planinsic RM, Damian D, Dai F, Tyurina YY, et al $\mathrm{N}$-acetylcysteine does not prevent hepatorenal ischaemia-reperfusion injury in patients undergoing orthotopic liver transplantation. Nephro Dial Transplant. 2010;25(7):2328-33. http://dx.doi.org/10.1093/ndt/ gfq077

7. Noël C, Hazzan M, Coppin MC, Codaccioni MX, Pruvot FR, Labalette $\mathrm{M}$, et al. A randomized controlled trial of pentoxifylline for the prevention of delayed graft function in cadaveric kidney graft. Clin Transplant. 1997:11(3):169-73. 